\title{
SOBRE A REFORMA PSIQUIÁTRICA BRASILEIRA: história e âmbitos atuais de luta
}

\author{
$*$ \\ Daniele Andrade Ferrazza \\ Faculdades Integradas de Ourinhos - FIO - Brasil \\ Universidade Paulista - UNIP - Brasil \\ Luiz Carlos da Rocha \\ Universidade Estadual Paulista Júlio de Mesquita Filho - Unesp - Brasil
}

\begin{abstract}
Resumo
O presente artigo tematiza a Reforma Psiquiátrica Brasileira por meio do recurso metodológico de inspiração foucaultiana de aproximar-se de um tema pelos atuais conflitos que apresenta, examinar as posições em embate pela exploração de suas histórias constitutivas e, com base na compreensão crítica assim obtida, operar a desconstrução do estabelecido e dispor perspectivas alternativas. Dessa forma, a Reforma Psiquiátrica foi aqui abordada por meio da revisita à história constitutiva dos dois pólos que nela se defrontam: de um lado, a perspectiva hospitalar psiquiátrica de enfrentamento da doença mental, examinada como um aggiornamento do manicomialismo; do outro, o modelo da Atenção Psicossocial, em sua ênfase reformadora de acolhimento transdisciplinar à pessoa em sofrimento psíquico. À guisa de conclusão, propõe-se que esse enfrentamento pode ser entendido como o confronto entre uma forma de contenção de origem carcerária e um modelo de acolhimento historicamente forjado em lutas contra o autoritarismo e a opressão.
\end{abstract}

Palavras-chave: Reforma Psiquiátrica Brasileira; Manicomialismo; Atenção Psicossocial.

\section{Introdução}

Polêmica e controversa, a Reforma Psiquiátrica Brasileira pode ser compreendida como uma manifestação nacional do processo global, sempre diferenciado e característico em cada formação social, de desmonte da imensa estrutura manicomial que dispôs, desde o século XIX, a internação psiquiátrica como meio de enfrentamento dos aflitivos problemas relacionados à loucura e ao sofrimento psíquico. Entre nós, esse movimento reformista que tem como marco importante a Lei 10.216 de 2001, tem apresentado o modo de Atenção Psicossocial como perspectiva interdisciplinar de cuidado personalizado proposto aos Centros de Atenção Psicossocial (CAPS) como forma alternativa às internações em leitos psiquiátricos propugnadas pelo aggiornamento das posições manicomialistas da psiquiatria tradicional. Longe de pretender responder a toda complexidade envolvida nas perspectivas que se defrontam, este artigo tem o objetivo de tematizar a Reforma Psiquiátrica Brasileira por meio 
do recurso metodológico de inspiração foucaultiana de aproximar-se de um tema pelas circunstâncias atuais dos conflitos que apresenta, desenvolver o exame das posições em embate por meio da exploração de suas histórias constitutivas e, com base na compreensão crítica que esse percurso possibilita, dispor perspectivas de desconstrução do estabelecido e de constituição de saberes-fazeres alternativos. Dessa forma, a reflexão que ora se apresenta se organiza em três partes.

A primeira procura explorar a história do encarceramento manicomial da loucura no Brasil desde o período colonial, com o cuidado de cotejar os momentos brasileiros com os da constituição dos saberes e práticas médico-psiquiátricas no panorama europeu que lhe serviu de base. Especial atenção será dada ao período higienista, que a exemplo do higienismo europeu, conduziria a formidável extensão das práticas psiquiátricas a amplos contingentes populacionais e, entre nós, expandiria as intervenções manicomiais aos principais centros nacionais.

A segunda aborda as origens e a consolidação do movimento da Reforma Psiquiátrica Brasileira, cujas críticas ao modelo asilar e as práticas tirânicas da psiquiatria tradicional se constituíram em elementos para a construção de novas práticas reformadoras da atenção em saúde mental, como a Atenção Psicossocial.

A terceira parte adota a perspectiva de Amarante $(2007 ; 2009 b)$ para refletir sobre os diversos campos de desenvolvimento da Reforma Psiquiátrica e da construção do modo de Atenção Psicossocial que, no âmbito da Saúde Mental, tem-se apresentado como principal contraposição ao modelo médico psiquiátrico tradicional.

\section{Elementos da Constituição Histórica da Psiquiatria no Brasil}

A situação da loucura no Brasil colônia pouco diferia da européia antes do século XVII, época em que os loucos constituíam um elemento comum à vida cotidiana e vagavam livremente na condição de errantes, a loucura era vista como pertencente à paisagem urbana $\mathrm{e}$ rural, e só excluída do convívio no caso de perigosa. Mas se no panorama europeu o século XVII assinala a inclusão da loucura na clientela forçada das casas de internação de pobres, não parece que essa condição humana conduzisse seu portador, na vastidão do Brasil colônia, à internação institucional. Já existiam, no Brasil de então, as Santas Casas de Misericórdia, que desde o século XVI cumpriam um papel semelhante a outros internatos gerais europeus, encerrando velhos, órfãos, mendigos e doentes. Mas não consta que dentre os internos estivessem os tocados pela loucura (RESENDE, 1987). 
Mas essa situação de relativa liberdade não resistiria à transferência da família real portuguesa para o Rio de Janeiro em 1808, quando a corte traria para o Brasil a instituição européia de enclausuramento daqueles que, por qualquer razão, representassem perigo ou qualquer preocupação à ordem pública. Desde então, seriam estabelecidas medidas de controle social com a finalidade de excluir tipos de existência que pudessem inquietar a ordenação das populações das cidades de interesse para a corte (DAÚD Jr., 2011). O louco, outrora tolerado, viria a engrossar o contingente de pobres, vagabundos e incapacitados que representassem ameaça à ordem urbana que, então, se instalava. E a loucura, de problema afeito às amplas e variadas condições da sociabilidade, começaria a experimentar aqui a condição de objeto de intervenção do Estado que já amargava em praticamente todo o continente europeu (AMARANTE, 1994). Aqui, seriam os porões das Santas Casas de Misericórdia que, com a entrada do século XIX, passariam a encerrar a loucura (RESENDE, 1987). Dessa forma, a partir de então, essas instituições de caridade e também de contenção, passariam a enclausurar a loucura em condições muito semelhantes àquelas dos antigos internatos comuns europeus, que Foucault (1972) denominaria de "o grande enclausuramento de pobres", instituição matricial onde localizaria o recorte criador dos manicômios, das penitenciárias e das demais instituições características da sociedade disciplinar europeia do século XIX. No Brasil, o controle disciplinar da loucura seria introduzido um pouco mais tarde.

A partir de 1830, a recém-criada Sociedade de Medicina e Cirurgia do Rio de Janeiro investirá em protestos contra a situação dos loucos nas Santas Casas de Misericórdia e, a exemplo da medicina alienista europeia, irá reivindicar para si o domínio da loucura (MACHADO et al., 1978). A medicina daqui, como a europeia fizera com suas Bicêtres e Salpêtrières, esgrimia o argumento de que as Santas Casas de Misericórdia não ofereciam estrutura para promover a cura daquela condição que, vista como doença, deveria ser posta em internação terapêutica em uma instituição destinada especificamente para seu tratamento. O pleito médico pela tutela da loucura culminaria na construção do Hospício D. Pedro II no Rio de Janeiro, inaugurado no ano de 1852, considerado um marco institucional da psiquiatria brasileira (AMARANTE, 1994; MACHADO et al., 1978; RESENDE, 1987). Logo, outras instituições psiquiátricas seriam inauguradas em diversas localidades do país, expandindo também no Brasil o manicomialismo de matriz pineliana que, com a europeização do mundo, estava se tornando global.

O hospício, principal instrumento terapêutico da psiquiatria emergente será, a partir de então, também no Brasil o espaço institucional de controle do louco onde se legitimará o 
discurso médico-psiquiátrico no controle e administração dessa contingência humana (FOUCAULT, 2006).

Machado et al. (1978), inspirados nos estudos de Michel Foucault sobre as instituições europeias, irão destacar cinco aspectos principais na organização da vida asilar brasileira. O primeiro é o estabelecimento do isolamento institucional, que promove a separação do louco do meio social e familiar. O segundo, a organização do espaço interno da instituição, onde os doentes seriam distribuídos de forma ordenada e regular. O terceiro, a vigilância do louco em todos os momentos e lugares. O quarto, a distribuição do tempo, evitando-se o perigo do ócio do agora doente através da prescrição de uma ocupação regrada e sistemática. Finalmente, o quinto, compõe a repressão, o controle e a individualização obtidas por meio do estabelecimento de normas e comportamentos considerados adequados, principalmente, à dependência e submissão do alienado à figura suprema do médico (MACHADO et al., 1978). Essa ordem disciplinar sempre seria considerada o cerne do tratamento moral, a terapêutica fundadora do manicomialismo e constituidora da psiquiatria que, muito convenientemente, só poderia atingir seus objetivos terapêuticos nessa configuração hierárquica e rigidamente regrada de espaço e de poder que teria como centro a autoridade médica (FOUCAULT, 2006).

O tratamento da loucura nessas instituições, uma vez que as sangrias e vomitórios da medicina da época não se adaptavam bem a esse novo domínio, ficava circunscrito às práticas de coerção, contenção e punição. Tais métodos, coadjuvados à imposição do trabalho forçado nas colônias agrícolas, iriam constituir a base do tratamento moral nas instalações brasileiras, fazendo um eco um tanto agrário a sua matriz europeia. Repetiam-se, contudo as bizarrices consideradas terapêuticas à época: os banhos muito frios ou muito quentes, a aplicação de "capacetes de gelo", a "malarioterapia”, que consistia na inoculação da malária no organismo de pacientes para que suas crises afastassem a loucura, a aplicação de injeções de morfina e de outras substâncias sedativas, o isolamento em solitárias chamadas de "quartos terapêuticos" e, por fim, a "traumaterapia", macabra conquista da psiquiatria brasileira, "orgulhosamente" descoberta pelo médico Franco da Rocha, que resume bem o caráter dos recursos terapêuticos manicomiais: consistia em uma violenta pancada na boca do estômago do paciente, da qual advinha aquela imobilidade contida que gratificava a expectativa de tranquilidade da psiquiatria de então (CUNHA, 1986).

Da legitimação do poder médico dentro da instituição asilar, os alienistas brasileiros partiriam, também, para a organização do espaço social (DAÚD Jr., 2011; COSTA, 2007). A 
ofensiva da psiquiatria para além dos muros dos hospícios constituirá um discurso médico de moralização e disciplinarização das camadas populares que, como no higienismo europeu, mas quase meio século mais tarde, atingirá todas as instâncias da vida cotidiana brasileira:

\footnotetext{
Autorizada por seu caráter científico, a medicina higiênica - como a medicina mental - vai constituir um discurso sobre todas as instâncias da vida, invadindo a esfera das relações pessoais para moldá-las segundo os propósitos da ordem e da disciplina urbanas. (...) Elas transitam por diferentes questões e iniciativas que incidem sobre o cotidiano da vida urbana, da habitação à saúde, da sexualidade à norma familiar, do crime às mobilizações operária, do medo das turbas e multidões ao receio à loucura, à promiscuidade, à devassidão. (CUNHA, 1986, p. 35).
}

\subsection{As Práticas Higienistas e a Ampliação do Alcance Psiquiátrico}

No Brasil, foi no início do século XX que a intervenção da psiquiatria no campo social se tornaria ainda mais ampla com o advento das concepções e práticas inspiradas no movimento higienista da Europa. Em traços rápidos, higienismo europeu foi o movimento que, desde o início do século XIX, caracterizou-se pela reforma sanitária, urbanística e arquitetônica das grandes formações urbanas europeias. Mas seus aspectos médico-sociais seriam marcantes principalmente a partir da segunda metade daquele século, quando as concepções da teoria da degenerescência de Morel conduziriam as técnicas manicomiais, antes restritas aos muros asilares, às grandes concentrações populares. A transformação deu caráter de medicina de população ao disciplinarismo alienista, agora fortalecido por noções do determinismo organicista e de um profundo pessimismo terapêutico que convidava à inevitabilidade de uma intensa ação de "profilaxia ativa", que alçaria os valores do tratamento moral a princípios de higiene moral das populações pobres (BERNARDES et al., 2009).

Sob a mesma perspectiva, a medicina higiênica e sua psiquiatria também farão o cerne da racionalidade nos investimentos de saneamento das cidades brasileiras que, à época, estavam em acelerada expansão. As concentrações de cortiços e favelas que marcavam o ambiente urbano logo foram consideradas focos de doenças infecciosas e sinais do perigo representado pela aglomeração da população de maltrapilhos e desempregados (RESENDE, 1987). Os processos de saneamento das cidades e de disciplinarização da vida cotidiana levariam ao recolhimento e ao enclausuramento daqueles que fossem considerados ameaça de desordem, o que atingia até mesmo aquele remanescente improdutivo da força de trabalho, seu exército de reserva, que aqui era tratado no âmbito geral da chamada vadiagem (DAÚD Jr., 2011). Toda essa sistemática de organização do espaço público estaria fundamentada em uma racionalidade que permitiria ao saber psiquiátrico apresentar-se como saber capaz de 
medicalizar todo tipo de comportamento social que se distanciasse das normas da moral e da disciplina, essencialmente daquela população pobre (BERNARDES et al., 2009).

A psiquiatria alienista brasileira, que já incluíra como um de seus fundamentos a teoria da degenerescência moreliana, estenderia seu domínio para as grandes concentrações populares e legitimaria um discurso de perigo social e de risco eugênico sobre as populações pobres que habitavam as grandes cidades (DAÚD Jr., 2011; COSTA, 2007; CUNHA, 1986).

As propostas de intervenção psiquiátrica e de prevenção da doença mental focadas nas populações pobres não era puro acaso. Desde sua origem européia o projeto psiquiátrico de profilaxia da enfermidade mental sempre esteve centrado nas populações miseráveis, conforme o legado de Morel que, em meados do século XIX, a partir das observações do proletariado pobre de regiões manufatureiras da França, construíra as concepções de "profilaxia ativa" dos desvios doentios pelos quais se interpretava os males da miséria de então (CASTEL, 1978; AUTOR, 1997). A profilaxia consistia na moralização e vigilância da população para o controle reprodutivo da degeneração hereditária vista à época como causa geral da doença mental.

A fundamentação na idéia de predisposição hereditária à doença mental, que constituiria a base da nova classificação psiquiátrica, abriria caminhos para a psiquiatria brasileira adotar as concepções e os projetos eugênicos como forma de, supostamente, enfrentar o problema daquela degeneração congênita que a própria psiquiatria havia inventado e desenvolvido na segunda metade do sec. XIX para explicar a miséria popular europeia (VENÂNCIO, 2003).

A psiquiatria alienista brasileira procuraria adaptar os conceitos de higiene social para o campo da profilaxia da doença mental e deslocaria seus discursos e suas práticas para além dos domínios médicos tradicionais. Dessa forma, o alvo de cuidados dos psiquiatras deixaria de ser exclusivamente o sujeito considerado "doente" e passaria a englobar também o indivíduo tido como normal, ou seja, aquele suspeito ainda não acometido dos males insidiosos da loucura (COSTA, 2007). No processo de prevenção da loucura, a psiquiatria ampliaria seu campo de abrangência para além das instituições manicomiais, para intervir na família, na educação, nas disposições 'raciais', na vida social como um todo (DAÚD Jr., 2011; COSTA, 2007; BOARINI, 2006). Isso proporcionará à psiquiatria brasileira uma extraordinária expansão de seu alcance diagnóstico, um passo marcante do expansionismo médico que produzirá a ampla medicalização do social característica das sociedades contemporâneas (GALINDO et al., 2014; AUTORES, 2010). 
A institucionalização das concepções higienistas e eugenistas iria culminar na organização de associações que desenvolveriam estudos e investiriam em programas de higienização e eugenização da população, com o propósito de supostamente conquistar a perfeição física e moral da nação brasileira. Dessa forma, para evitar à propagação de indivíduos degenerados, as medidas eugênicas caberiam perfeitamente nos propósitos médicos. Os principais objetivos dos programas eugênicos eram preservar as gerações futuras das doenças, que seriam transmitidas hereditariamente, e promover o aperfeiçoamento da 'raça' (BOARINI, 2006). Para a conquista de tais intenções seria necessário regenerar a população através do controle da sua reprodução, o que compreendia um conjunto de ações eugênicas:

movidos pelo ideal de aperfeiçoamento do homem brasileiro, os psiquiatras da LBHM [Liga Brasileira de Higiene Mental] vão definindo seu campo de ação, elegendo certos temas como prioritários, na tarefa de garantir a "defesa da mentalidade da raça", combate ao alcoolismo e aos "vícios sociais"; imigração selecionada; controle dos casamentos (para prevenir uniões indesejáveis, bem como incentivar as eugenicamente desejáveis); esterilização compulsória dos ditos degenerados; seleção e orientação profissional; atenção à infância para um desenvolvimento mental sadio e eugênico. (REIS, 2003, p. 186).

Essas práticas higienistas e eugenistas do alienismo brasileiro culminariam na construção de novos hospitais psiquiátricos e na ampliação dos já existentes.

A psiquiatria, na década de 30, ainda encontraria novos recursos pretensamente terapêuticos. É a época da descoberta do choque insulínico, do choque cardiazólico e, depois, da eletroconvulsoterapia e das lobotomias. Na década de 50, a descoberta da clorpromazina fortaleceria ainda mais o processo de psiquiatrização do sofrimento psíquico com o uso desse fármaco para tornar os internos mais dóceis e a instituição manicomial mais tranquila e administrável (GALINDO et al., 2014; AMARANTE, 1994). Mais tarde, nos anos 80, a psiquiatria encontrará nos psicofármacos a possibilidade de realização de seu sonho de reintegrar-se à medicina, da qual se distanciara pelas práticas e concepções alienistas do século XIX. No Brasil, a perspectiva medicamentosa será considerada pela psiquiatria nacional como o recurso terapêutico possibilitador da redução das internações psiquiátricas implementadas, na verdade, pela Luta Antimanicomial e pelas consequências das várias experiências internacionais de Reforma Psiquiátrica - de François Tosquelles a Franco Basaglia - que se apresentaram em reação à brutalidade das técnicas manicomiais, motivadas por passagens históricas especialmente traumáticas para toda a humanidade. Pois, de fato, é inegável que o principal motivo do desmonte manicomial iniciado na segunda metade do século XX foi a desconcertante semelhança de seus métodos e técnicas com o manejo dos 
campos de concentração que estarreceram a opinião pública no pós-guerra (AMARANTE, 2008; BOARINI, 2006).

De qualquer forma, é possível perceber que, nos dias atuais, a perspectiva de abordar o sofrimento psíquico exclusivamente pela via medicamentosa tenda a fazer de qualquer sinal de mal-estar uma possibilidade de diagnóstico psiquiátrico seguida de pronta e continuada prescrição de psicofármacos (AUTORES, 2010). Vive-se, sem dúvida, tempos de banalização diagnóstica e generalizada medicalização da sociedade. Entretanto, mercê da história de desconstrução das tradições de aprisionamento herdadas dos séculos passados, assiste-se à redução de instituições manicomiais em todo país, ainda que ecoem insistentes reclamos da psiquiatria tradicional por mais verbas públicas para leitos psiquiátricos em hospitais privados. Mas essa é uma reivindicação movida por motivos muito menos técnicos e assistenciais do que por interesses de mercado vinculados à velha tradição brasileira que, herdeira do manicomialismo, consorcia o empresariado dos hospitais privados a setores corporativos da medicina, bem por isso, adversários da Reforma Psiquiátrica.

\section{O Movimento da Reforma Psiquiátrica Brasileira: história e conquistas}

A denominação Reforma Psiquiátrica Brasileira, a despeito de tratar-se de expressão consagrada na literatura especializada (RINALDI, 2015; COSTA-ROSA, 2013; BEZERRA, 2011; LOBOSQUE, 2011; PITTA, 2011; AMARANTE, 2009a) está longe de identificar um pensamento de tipo doutrinário ou mesmo homogêneo. Pelo contrário, a expressão abarca contribuições provenientes de uma pluralidade de aportes teórico-metodológicos e de variadas experiências junto aos problemas da Saúde Mental, que têm em comum duas características intimamente relacionadas: uma ponderada crítica antimanicomial e uma esperança de que pessoas em sofrimento psíquico possam receber acolhimento adequado às suas necessidades sem que isso implique em sua redução a estereotipias profissionais e a interesses corporativos.

A Reforma Psiquiátrica Brasileira tem sua origem recente no final da década de 70 , onde se desenvolveu junto a outros movimentos sociais que lutavam contra o autoritarismo implantado pelo golpe militar de 1964, pela democratização do país e, de modo geral, pela efetivação de direitos populares às conquistas de nossa civilização. No contexto do enfrentamento do autoritarismo ditatorial, emergiriam as críticas ao sistema público de saúde, onde despontava o inconformismo com as péssimas condições a que eram submetidos os doentes mentais enclausurados nos hospitais psiquiátricos. 
No ano de 1978, em meio à denúncia da trágica e desumana situação vivida pelos reclusos de um grande hospital psiquiátrico, nasce o Movimento dos Trabalhadores em Saúde Mental (AMARANTE, 2009a). O movimento, que seria conhecido pela sigla MTSM, denunciava o abandono, a violência, e os maus-tratos a que eram submetidos os internos e revelaria, também, a utilização de instituições psiquiátricas como instrumentos do aparelho repressivo da ditadura militar (DAÚD, Jr., 2011). O movimento se organizaria para requerer melhores condições de trabalho, desenvolveria críticas ao uso do eletrochoque, denunciaria a cronificação produzida pelo manicômio e reivindicaria a humanização dos serviços de saúde mental, para promover melhores condições de assistência à população. Identificado como um marco importante do movimento da Reforma Psiquiátrica, conforme Amarante (2009a), o MTSM teria presença marcante em todos os outros acontecimentos que fariam avançar a luta contra o caráter manicomial da assistência psiquiátrica.

No final da década de 80, congressos, encontros e conferências de saúde seriam espaços de intensas discussões nas quais se definiriam propostas de reorganização da assistência em saúde mental, com prioridade para o sistema extra-hospitalar e para um modelo assistencial que revertesse o caráter organicista e medicamentoso dos procedimentos terapêuticos. O MTSM perceberia a necessidade de transformar-se em um movimento social com o intuito de envolver e comprometer toda a sociedade na discussão das formas tradicionais de lidar com a loucura e na construção de alternativas para a atenção em saúde mental. Dessa iniciativa, seria criado o Movimento da Luta Antimanicomial, que assumiria como lema principal uma bandeira tão ao gosto de Basaglia, que falecera no início daquela década: "por uma sociedade sem manicômios".

$\mathrm{Na}$ busca da superação de soluções exclusivamente técnicas e administrativas, seriam enfatizadas a criação de novos dispositivos de saúde e novas tecnologias de cuidado com objetivo de superar aquelas restritas ao saber médico-psiquiátrico tradicional:

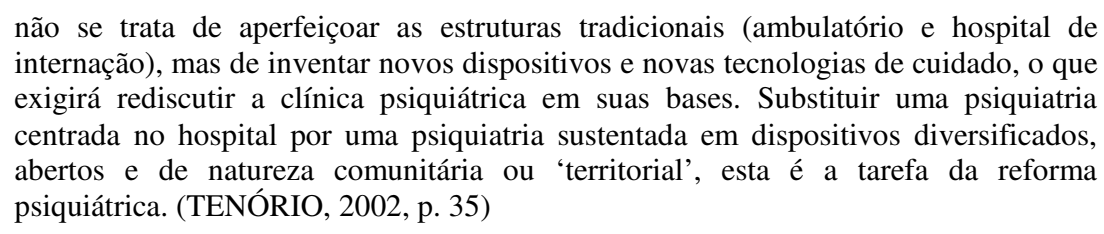
internação), mas de inventar novos dispositivos e novas tecnologias de cuidado, o que exigirá rediscutir a clínica psiquiátrica em suas bases. Substituir uma psiquiatria centrada no hospital por uma psiquiatria sustentada em dispositivos diversificados, abertos e de natureza comunitária ou 'territorial', esta é a tarefa da reforma psiquiátrica. (TENÓRIO, 2002, p. 35)

Nessa configuração, vários municípios brasileiros, no final da década de 80 , desenvolveriam novas experiências no âmbito da saúde mental. Compromissadas com diversos desafios, tais experiências criaram novos dispositivos de cuidado ao sujeito em sofrimento psíquico e construíram a possibilidade de um novo lugar social para a loucura que não fosse o da anormalidade, da periculosidade, do erro, da incapacidade. Essas experiências 
demarcaram novas formas de intervenção no campo da saúde mental e proporcionaram a construção do modelo de Atenção Psicossocial (COSTA-ROSA, 2013).

A ação criativa desse movimento reformista fez tramitar no Congresso Nacional a Lei da Reforma Psiquiátrica. O projeto de lei $\mathrm{n}^{\circ} 3.657 / 89$, proposto pelo deputado Paulo Delgado em nome da pluralidade compreendida nessa luta, era constituído por três artigos. O primeiro previa a extinção progressiva dos manicômios e impedia a criação de novos hospitais psiquiátricos, o segundo previa o redirecionamento dos recursos públicos para os serviços substitutivos e o terceiro obrigava a comunicação das internações compulsórias à autoridade judiciária, única instância aceitável às decisões sobre a liberdade no contexto da sociedade de direito (TENÓRIO, 2002).

Em virtude das dificuldades de aprovação no Senado, esse projeto de lei, objeto de diversas emendas e substitutivos, seria aprovado somente doze anos depois, em 2001. A lei aprovada, Lei 10.216/01, não contemplava a extinção progressiva dos manicômios e não estabelecia as condições para internação psiquiátrica nos termos definidos pelo projeto original. Entretanto, apesar da solução de compromisso típica do funcionamento legislativo em democracias representativas, essa lei representou um importante passo para o processo da Reforma Psiquiátrica Brasileira e para todo atendimento nacional em saúde mental.

Após a aprovação da Lei 10.216/01, conhecida como a Lei da Reforma Psiquiátrica, outras portarias do Ministério da Saúde regulamentariam a criação de serviços substitutivos ao hospital psiquiátrico como os Centros de Atenção Psicossocial (CAPS) e as Residências Terapêuticas, além do estabelecimento de projetos de geração de renda e trabalho e de benefícios financeiros vinculados ao Programa "De volta pra casa". São dispositivos onde a criatividade conjunta de trabalhadores e usuários, no que pesem as dificuldades instituintes do novo, tem a possibilidade de forjar melhores caminhos de atenção no âmbito da saúde mental.

Em 1987 foi instalado o primeiro CAPS, uma unidade inovadora implantada na cidade de São Paulo e que recebeu o nome de Luiz Cerqueira, entusiasta da Reforma Psiquiátrica desde sua origem e Coordenador de Saúde Mental de São Paulo no ano de 1973. Na última década assistimos a instalação de CAPS nos mais diversos municípios do país e em 2012 podiam ser contabilizados 1.803 unidades em todo país (BRASIL, 2012). O progresso na instalação desses serviços substitutivos se faz acompanhar, também, por claros sinais de desconstrução dos dispositivos de caráter manicomial e assemelhados. Os leitos psiquiátricos, que em 2002 somavam 51.393, foram reduzidos a 29.958 em 2012 (BRASIL, 2012). Ainda assim, são inúmeros os desafios a serem enfrentados pela Reforma Psiquiátrica Brasileira que, 
inegavelmente, enfrenta uma acirrada oposição de segmentos sociais e de associações coorporativas que tentam destruir as bases de sustentação da Política Nacional de Saúde Mental que, como bem aponta Bezerra (2011), é reconhecida mundialmente como bem sucedida. Longe de limitar-se a uma questão meramente assistencial, a luta pela Reforma Psiquiátrica é hoje compreendida como um processo social complexo que demanda ações de âmbito teórico, técnico, político, jurídico e sociocultural. É da complexidade dessas perspectivas de luta que se deve tratar agora.

\section{Reforma Psiquiátrica: as dimensões da práxis reformadora}

O movimento da Reforma Psiquiátrica deve ser compreendido como um processo social complexo, que abrange diferentes âmbitos e demanda ações em campos diversos. Costa-Rosa (2013) considera que esses âmbitos compreendem ações nos campos teóricoprático, político-ideológico e ético norteadas pela superação da hegemonia do paradigma por ele denominado hospitalocêntrico medicalizador. No mesmo sentido, Amarante (2009b; 2007) considera que o processo de construção de uma Atenção Psicossocial requer o entrelaçamento de ações transformadoras nas dimensões teórico-conceitual, técnico-assistencial, políticojurídica e sociocultural. Aqui, tomar-se-á como referência o modelo dos quatro campos de ações e reflexões propostas por Amarante (2007), no qual esta reflexão baseia-se amplamente.

As transformações no campo teórico-conceitual compreendem o questionamento do paradigma psiquiátrico e o trabalho meticuloso de desconstrução do arcabouço conceitual sobre doença mental e mal-estar psíquico sustentado pela psiquiatria e pela psicologia tradicionais. Essa disposição reformadora compreende que a história constitutiva da psiquiatria mostra o desenvolvimento de um processo de apropriação do fenômeno da loucura e do sofrimento psíquico humano por parte de saberes e práticas de base corporativa que transformaram uma contingência humana em objeto exclusivo de saberes e práticas institucionais da medicina psiquiátrica e da psicologia clínica tradicionais (KYRILLUS NETO; SANTOS, 2014; COSTA-ROSA, 2013; YASUI, 2010).

Basaglia (1985) já trazia a denúncia de que a psiquiatria tendia a colocar o sujeito entre parênteses e focar a "doença", sem interagir com o que ele chamava de existência sofrimento. E propunha o movimento inverso: colocar a "doença mental entre parênteses" para olhar a "existência sofrimento do sujeito" dentro das complexidades e especificidades que a constituem (AMARANTE, 2007). 
A disposição de colocar a "doença entre parênteses" e olhar para o sujeito em sua experiência, com suas vicissitudes, com seus problemas cotidianos, com seus projetos e anseios próprios da singularidade da aventura humana significa ampliar a noção de integralidade em saúde mental (AMARANTE, 2007; VENTURINI, 2010) e romper com práticas essencialmente prescritivas de psicofármacos e de psicoterapias. Nessa perspectiva, os dispositivos de atendimento em saúde mental deixariam de ser lugares de exclusão, de repressão, de disciplinamento, de moralização e de medicalização estereotipadas para se constituírem como lugares especialmente propícios ao acolhimento da problematização inerente ao processo de construção subjetiva do ser humano (ROSA; VILHENA, 2012; BEZERRA, 2011; PITTA, 2011). O próprio fato de não limitar-se ao maniqueísmo doençacura, do normal-patológico, possibilitaria a construção de outras formas de acolhimento do sujeito que não fosse apenas a remissão de sintomas através da prescrição de medicamentos que remediariam uma existência considerada marcada pelo desvio, pelo defeito e pelo transtorno de uma suposta normalidade do ser humano, nessa perspectiva já reduzido ao seu funcionamento neurofisiológico.

Dessa forma, a produção de outros conceitos e práticas tem sido uma das preocupações fundamentais da Reforma Psiquiátrica. A proposta compreende a construção de um novo campo teórico-conceitual, estabelecendo um intenso diálogo horizontal entre as diferentes disciplinas e experiências que possam contribuir para a compreensão e atendimento do sujeito em sofrimento psíquico (YASUI, 2010). Nesse âmbito, aqueles serviços de saúde mental, antes constituídos por uma equipe multiprofissional na qual cada profissional atuava no âmbito restrito de sua especialidade formal, deveriam ceder espaço para a organização de uma equipe de saúde interdisciplinar com atuação transdisciplinar (COSTA-ROSA, 2013). Na perspectiva dessa transdisciplinaridade, as ações da equipe deixariam de ser centradas na consulta psiquiátrica ou na aplicação de procedimentos psicoterápicos para se focarem nas necessidades e especificidades do sujeito em sofrimento psíquico. Nessa perspectiva, a transdisciplinaridade "subverte o eixo de sustentação dos campos epistemológicos, graças ao efeito de desestabilização tanto da dicotomia sujeito/objeto quanto da unidade das disciplinas e dos especialismos". (PASSOS; BARROS, 2000, p.76).

Nesse contexto, a transformação do campo técnico-assistencial deve focar a construção de uma rede de novos serviços substitutivos àqueles centrados no modelo médico tradicional e nas práticas manicomiais que lhe deram origem. A proposta é a de construção de serviços territoriais que visem à sociabilidade daqueles antes excluídos da diversidade da convivência social pelo estigma da "doença mental". A proposta compreende romper com as 
práticas disciplinares, moralizantes, medicalizadoras e psicopatologizantes e promover ações que garantam a possibilidade desse sujeito em sofrimento psíquico ser cuidado nos espaços sociais que promovam seu desenvolvimento como sujeito de sua própria existência (VENTURINI, 2010). Esses são alguns dos princípios orientadores dos projetos dos Centros de Atenção Psicossocial (CAPS), dispositivos compreendidos como estratégicos para a Rede de Atenção Psicossocial em saúde (COSTA-ROSA; YASUI, 2008).

No entanto, é preciso destacar que a implantação de CAPS em território nacional não significa, necessariamente, o total engajamento dessas instituições com os princípios de uma Atenção Psicossocial, pois esses serviços, mesmo considerados substitutivos à internação manicomial, podem limitar sua ação a uma reprodução de práticas tradicionais da psiquiatria. Desta forma, é conveniente considerar que os CAPS são apenas mais uma das estratégias de uma Rede de Atenção Psicossocial, ampla e complexa, que envolve a articulação com outras instituições e novos dispositivos responsáveis pelas ações coletivas em um determinado território (OLIVEIRA; CALDANA, 2014; COSTA-ROSA, 2013; BEZERRA, 2011; YASUI, 2010). A superação do paradigma manicomial supõe o reconhecimento das demandas concretas dos usuários de um determinado território e a criação de práticas criativas, diversificadas e entrelaçadas em uma rede, em um conjunto de ações denominadas por diversos autores como "clínica ampliada” (BEZERRA, 1996; ONOCKO-CAMPOS, 2001; TENÓRIO, 2002). A “clínica ampliada” é um dispositivo que requer a expansão de suas intervenções para além do espaço restrito dos serviços de saúde. A proposta é de adentrar-se nos diversos espaços territoriais e nos seus diferentes âmbitos políticos, econômicos, sociais, culturais, geográficos, demográficos, com o intuito de que essas intervenções se articulem aos diferentes sujeitos que apresentam seus próprios interesses, necessidades, desejos e sonhos (ONOCKO-CAMPOS, 2001).

As transformações dos serviços no âmbito da saúde mental também se vinculam a desafios no campo político-jurídico. A aprovação da lei 10.216/01 e de portarias que regulamentam a implantação dos serviços substitutivos à internação e a constituição de uma rede de atenção e cuidados em saúde mental foi uma grande conquista no campo legislativo da Reforma Psiquiátrica. No entanto, é necessária a revisão de toda a legislação, eivada de referências prejudiciais aos sujeitos em sofrimento psíquico ou portador de diferenças legalmente definidas como deficiências (COSTA-ROSA, 2013).

Mas é no âmbito muito mais geral do espaço sociocultural que a Reforma Psiquiátrica disputa suas condições históricas de real viabilidade. É preciso apoiar a construção de práticas sociais que visem à transformação do imaginário social em tudo que se 
relaciona com as palavras loucura, doença mental, deficiência, para abrigar essas noções no âmbito mais geral e compreensivo das diferenças e das contingências da vida humana. $O$ ocaso, ainda que tardio, dos manicômios é uma tendência brasileira e mundial. Mas Franco Basaglia já percebia que, para além da necessidade de demolição da estrutura física das instituições manicomiais havia o desafio da desconstrução da própria "psiquiatria enquanto ideologia" (AMARANTE, 2008). São transformações que dependem da promoção de discussões de amplo alcance social, mas que também se beneficiam da presença cultural, artística e amplamente social de todos os atores envolvidos nesse processo. Nesse sentido, é de sensível importância a criação de grupos de intervenções artísticas (de teatro, de música, de artes plásticas) que congreguem usuários e técnicos de serviços de saúde mental, como também é fundamental a presença dessa pluralidade em todas as mídias e em todos os espaços de manifestação e de debate.

Cumpre notar, enfim, que a Reforma Psiquiátrica é bem mais que a mudança de noções teóricas, que a criação de novos serviços, que a reformulação de nossas normas legais. Pela complexidade de suas reverberações no seio social, ela tem papel importante na construção de uma nova sociabilidade mais aberta à especificidade da aventura humana e à pluralidade de suas circunstâncias.

\section{Considerações Finais}

A Reforma Psiquiátrica foi aqui abordada por meio da revisita à história constitutiva dos dois pólos que nela se defrontam. De um lado, a internação psiquiátrica, seja no seu formato original manicomialista, seja no seu feitio aggiornado, o hospitalar. Do outro, o movimento reformador e o modelo da Atenção Psicossocial, com sua ênfase no acolhimento transdisciplinar ao sofrimento psíquico. Espera-se que este artigo, longe de qualquer pretensão de ter esgotado a complexidade do tema, possa ter oferecido à reflexão do leitor duas contribuições aqui consideradas fundamentais. A primeira, isenta de novidade, é a reiteração de que a história da psiquiatria no Brasil responde, ainda que em tempo e em combinações diversas, ao formato básico da história da psiquiatria europeia, sobretudo em sua matriz francesa. Essa história é marcada pela internação alienista que, fundadora do manicomialismo, veio ao mundo como uma inevitável marca de herança da reclusão das casas de força que lhe foram ancentrais e, sobremaneira, matriciais. Mas tampouco há aqui alguma novidade, visto que essa herança do grande aprisionamento de pobres é central nas já clássicas análises de Foucault (2006; 1972) e Castel (1978), repercutidas entre nós - e particularizadas às condições brasileiras - por Machado et al. (1978), Costa (2007), entre outros. Mas esse registro obriga reconhecer que o internamento não foi, nem lá nem aqui, algo como uma 
escolha terapêutica mas, em ambos os casos, veio à luz como um tipo de herança carcerária. É dessa mera decorrência que se deriva a segunda contribuição deste artigo, que aqui se crê necessária a qualquer ponderação responsável sobre a polêmica que envolve a Reforma Psiquiátrica: é inevitável considerar que a propositura que se desenvolve em torno da internação hospitalar psiquiátrica não é e nunca foi o desenvolvimento ou a modernização de qualquer forma de terapêutica, mas só pode ser entendida no âmbito mais rude de um modo de contenção de origem carcerária. Assim, quando a forma de hospitalização psiquiátrica se defronta com a Atenção Psicossocial, assiste-se ao confronto entre uma forma de contenção e uma forma de atenção que, ainda que cheia de inegáveis insuficiências, tem sua origem em preocupações de acolhimento historicamente forjadas em meio a lutas contra o autoritarismo e a opressão. É, então, entre a contenção e o acolhimento que se debate a polêmica da Reforma Psiquiátrica Brasileira, e por certo não serão infensas às decorrências desse embate as esperanças de respeito à diferença e de justiça social tão caras às perspectivas da cidadania brasileira.

\title{
ON THE BRAZILIAN PSYCHIATRIC REFORM: current history and realms of struggle
}

\begin{abstract}
The current paper addresses the Brazilian Psychiatric Reform by means of methodological resource inspired by Foucault, which consists of approaching a theme through its current conflicts, examining the situations in shock by exploring their constitutive history, on the basis of the critical understanding so obtained, to operate the deconstruction of the established and make use of alternative perspectives. In this manner, the Psychiatric Reform was here approached through the revisit of the constitutive history of its opposite sides: the hospital psychiatric perspective of coping with the mental disease, examined as an aggiornamento of the asylum; and the Attention Psychosocial model, with its reformative emphasis in transdiciplinary reception of the person in psychic suffering. Concluding, it is proposed that this facing can be understood as the confront between a way of contention of prison origin and a model of reception historically shaped in the struggle against authoritarianism and oppression.
\end{abstract}

Keywords: Brazilian Psychiatric Reform; Asylum; Psychosocial Attention.

\section{SOBRE LA REFORMA PSIQUIATRÍCA BRASILEÑA: historia e esferas actuales de lucha}

Resumen: El presente artículo trata sobre la temática de la Reforma Psiquiátrica Brasileña por medio del recurso metodológico, de inspiración foucaultiana, que consiste en acercarse de un tema por los actuales conflictos que presenta, investigar las posiciones en pugna por la explotación de sus historias constitutivas y, basados en la comprensión crítica así obtenida, operar en la desconstrucción de lo establecido y proponer perspectivas alternativas. De esta 
manera, la Reforma Psiquiátrica fue aquí revisitada por medio de la historia constitutiva de dos extremos opuestos: de un lado, la perspectiva hospitalaria psiquiátrica de enfrentamiento de la enfermedad mental, examinada como un aggiornamiento del manicomialismo; por otro lado, el modelo de la Atención Psicosocial, en su énfasis reformadora de acogimiento transdisciplinar a la persona en sufrimiento psíquico. Como conclusión, se propone que ese enfrentamiento pueda ser comprehendido como el confronto entre una forma de contención de origen carcelaria y un modelo de acogimiento históricamente forjado en luchas contra el autoritarismo y la opresión.

Palabras-clave: Reforma Psiquiátrica Brasileña; Manicomialismo; Atención Psicosocial.

\section{REFERÊNCIAS}

AMARANTE, Paulo. Loucos pela vida: A trajetória da reforma psiquiátrica no Brasil (2a ed., $4^{\circ}$ reimpressão). Rio de Janeiro: Fiocruz, 2009a.

AMARANTE, Paulo. Reforma Psiquiátrica e epistemologia. Caderno Brasileiro de Saúde Mental, v. 1, n. 1, jan-abr., (CD-ROM), 2009b. Disponível em:

http://portal.incubadora.ufsc.br/index.php/cbsm/article/viewFile/998/1107. Acesso em 21 de jan. de 2012.

AMARANTE, Paulo. O homem e a serpente. Outras histórias para a loucura e a psiquiatria ( $3^{\circ}$ reimpressão). Rio de Janeiro: Fiocruz, 2008.

AMARANTE, Paulo. Saúde Mental e Atenção Psicossocial. Rio de Janeiro: Fiocruz, 2007.

AMARANTE, Paulo. Asilos, alienados, alienistas: uma pequena história da psiquiatria no Brasil. In: AMARANTE, Paulo. (Org.). Psiquiatria Social e Reforma Psiquiátrica. Rio de Janeiro: Fiocruz, 1994.

BASAGLIA, Franco. A instituição negada (H. Jahn, Trad., 3a ed.) Rio de Janeiro: Graal, 1995.

BERNARDES, Anita; PELLICCIOLI, Eduardo; GUARESCHI, Neuza. Saúde Pública: publicização do Brasil. Psicologia Política, v. 9, n.17, Jan.-Jun, 2009. Disponível em: http://www.fafich.ufmg.br/rpp/seer/ojs/viewarticle.php?id=75. Acesso em: 23 de mar. de 2012.

BEZERRA, Benilton. É preciso repensar o horizonte da Reforma Psiquiátrica. Ciência e Saúde Coletiva, v.16, n.12, p.4590-4602, 2011. Disponível em:

http://www.scielo.br/pdf/csc/v16n12/07.pdf. Acesso em: 12 de jan. de 2012.

BEZERRA, Benilton. A Clínica e a Reabilitação Psicossocial. In: PITTA, Ana. (Org.). Reabilitação Psicossocial no Brasil (pp. 137-142). São Paulo: Hucitec, 1996. 
BOARINI, Maria. L. A loucura no leito de Procusto. Maringá: Dental Press, 2006.

BOARINI, Maria. L.; YAMAMOTO, Osvaldo. H. Higienismo e Eugenia: discursos que não envelhecem. Psicologia Revista, v.13, n.1, p. 59-72. São Paulo: Educ, 2004.

BRASIL. Ministério da Saúde. Coordenação Geral de Saúde Mental, Álcool e Outras Drogas. Saúde Mental em Dados - 11, Ano VII, n 11, Out. 2012. Informativo eletrônico. Brasília, 21p. Disponível em: http://psiquiatriabh.com.br/wp/wp-content/uploads/2015/01/Dados-darede-assistencial-brasileira-2012-Ministerio-da-Saude.pdf. Acesso em: 04 de abr. de 2012.

CASTEL, Robert. A ordem psiquiátrica: A idade de ouro do alienismo. Rio de Janeiro: Graal, 1978.

COSTA, Jurandir. F. História da Psiquiatria no Brasil: um corte ideológico (5a ed. rev.) Rio de Janeiro: Garamond, 2007.

COSTA-ROSA, Abílio. Atenção Psicossocial além da Reforma Psiquiátrica. Contribuições a uma Clínica Crítica dos processos de subjetivação na Saúde Coletiva. São Paulo: Editora Unesp, 2013.

COSTA-ROSA, Abílio; YASUI, Silvio. A estratégia Atenção Psicossocial: desafio na prática dos novos dispositivos de Saúde Mental. Revista Saúde em Debate, v.32, n.78/79/80, p. 27 37, 2008.

CUNHA, Maria. C. P. O espelho do mundo: Juquery, a história de um asilo. Rio de Janeiro: Paz e Terra, 1986.

DAÚD, Jr. Nacile. Considerações histórico-conceituais sobre a instituição psiquiátrica no Brasil e a desinstitucionalização do "doente mental". In: BOARINI, Maria. L. (Org.).

Desafios na atenção à saúde mental. Maringá: Eduem, 2011.

AUTORES, 2010.

FOUCAULT, Michel. História da loucura na idade clássica. São Paulo: Perspectivas, 1972. FOUCAULT, Michel. O poder psiquiátrico: curso dado no Collège de France (1973-1974) (E. Brandão, Trad.). São Paulo: Martins Fontes, 2006.

GALINDO, Dolores.; LEMOS, Flávia, C. S.; RODRIGUES, Renata. V. Do Poder Psiquiátrico: uma analítica das práticas de farmacologização da vida. Mnemosine, v. $10, \mathrm{n}^{\circ} 1$, p. 98-113, 2014. Disponível em:

http://www.mnemosine.com.br/ojs/index.php/mnemosine/article/view/333/307. Acesso em 02 de fev., 2015.

KYRILLUS NETO, Fuad; SANTOS, Rodrigo, A. N. Lógica diagnóstica em serviços abertos de saúde mental: tensões entre psiquiatria e psicanálise. Barbarói, Santa Cruz do Sul, n.40, p.63-82, jan./jun., 2014. Disponível em:

https://online.unisc.br/seer/index.php/barbaroi/article/viewFile/3511/3541. Acesso em: 25 de Jan. 2014. 
LOBOSQUE, Ana. M. Debatendo alguns desafios da Reforma Psiquiátrica brasileira. Ciência e Saúde Coletiva, v.16, n.12, p.4590-4602, 2011. Disponível em:

http://www.scielo.br/pdf/csc/v16n12/03.pdf. Acesso em 12 de Jan. de 2012.

MACHADO, Roberto. et al. Danação da Norma: Medicina Social e Constituição da psiquiatria no Brasil. Rio de Janeiro: Graal, 1978.

OLIVEIRA, Thaís. T. S.; CALDANA, Regina, H. L. Práticas psicossociais em psicologia: um convite para o trabalho em rede. Pesquisas e Práticas Psicossociais, v.9, n.2, São João delRei, jul./dez., 2014. Disponível em: http://www.ufsj.edu.br/portal2-

repositorio/File/revistalapip/5\%20-\%20Art_\%20226\%20-\%20Pronto-resumo\%283\%29.pdf. Acesso em: 05 de mar. 2015.

ONOCKO-CAMPOS, Rosana. Clínica: a palavra negada - sobre as práticas clínicas nos serviços substitutivos de Saúde Mental. Saúde em Debate, v. 25, n.58, p. 98-111, 2001.

PASSOS, Eduardo; BARROS, Regina. B. A. A construção do plano da clínica e o conceito de transdisciplinariedade. Psicologia: Teoria e Pesquisa, v.16, n.1, p.71-79, jan./abr, 2000.

PITTA, Ana. M. F. Um balanço da Reforma Psiquiátrica Brasileira: instituições, atores e políticas. Ciência e Saúde Coletiva, v. 16, n.12, p.4579-4589, 2011. Disponível em: http://www.scielo.br/pdf/csc/v16n12/02.pdf. Acesso em: 12 de Jan. de 2012.

RESENDE, Hector. Política de saúde mental no Brasil: uma visão histórica. In: TUNDIS, S.A.; COSTA, N. R., Cidadania e Loucura: Políticas de Saúde Mental no Brasil. Petrópolis, RJ: Vozes; Abrasco, 1987.

REIS, José. R. F. Degenerando em barbárie: a hora e a vez do eugenismo radical. In: BOARINI, Maria. L. (Org.). Higiene e Raça como projetos: higienismo e eugenismo no Brasil. Maringá: Eduem, 2003.

RINALDI, Doris, L. Micropolítica do desejo: a clínica do sujeito na instituição de saúde mental. Ciência e Saúde Coletiva, v. 20, n.2, p. 315-323, 2015.

AUTOR, 1997.

ROSA, Carlos, M.; VILHENA, Junia. Do manicômio ao CAPS: da contenção (im)piedosa à responsabilização. Barbarói, Santa Cruz do Sul, n.37, p.154-176, jul./dez. 2012. Disponível em: https://online.unisc.br/seer/index.php/barbaroi/article/viewFile/2498/2361. Acesso em: 26 de Out. 2014.

TENÓRIO, Fernando. A reforma psiquiátrica brasileira, da década de 1980 aos dias atuais: história e conceitos. História, Ciências, Saúde - Manguinhos, v. 9, n.1, p. 25-59, jan/abr. 2002.

VENÂNCIO, Ana. T. A. História do saber psiquiátrico no Brasil: ciência e assistência em debate. História, ciências, saúde - Manguinhos, v. 10, n.3, 2003. Disponível em: http://www.scielo.br/pdf/hcsm/v10n3/19315.pdf. Acesso em: 03 de Set. de 2009.

VENTURINI, Ernesto. "O caminho dos cantos": morar e intersetorialidade na Saúde Mental. Fractal: Revista de Psicologia, v. 22, n.3, p. 471-480, 2010. Disponível em: 
http://www.uff.br/periodicoshumanas/index.php/Fractal/article/view/573/475. Acesso em 24 de Jan. de 2012.

YASUI, Silvio. Rupturas e encontros: desafios da Reforma Psiquiátrica Brasileira. Rio de Janeiro: Fiocruz, 2010.

Data de recebimento: 06/03/15

Data de aceite: $28 / 07 / 16$

\section{Sobre os autores:}

Daniele Andrade Ferrazza é Professora do Curso de Graduação em Psicologia das Faculdades Integradas de Ourinhos (FIO) e da Universidade Paulista (UNIP). Endereço eletrônico: danieleferrazza@yahoo.com.br

Luiz Carlos da Rocha é Professor Assistente Doutor da Faculdade de Ciências e Letras UNESP/Assis da Universidade Estadual Paulista Júlio de Mesquita Filho, campus Assis-SP. Endereço eletrônico: lcrocha@assis.unesp.br 